\title{
Male breast cancer in Cowden syndrome patients with germline PTEN mutations
}

James D Fackenthal, Deborah J Marsh, Anne-Louise Richardson, Shelly A Cummings, Charis Eng, Bruce G Robinson, Olufunmilayo I Olopade

\begin{abstract}
Cowden syndrome (CS) (OMIM 158350) is a multiple hamartoma syndrome associated with germline mutations in the PTEN tumour suppressor gene. While CS is characterised most commonly by noncancerous lesions (mucocutaneous trichilemmomas, acral and palmoplantar keratoses, and papillomatous papules), it is also associated with an increased susceptibility to breast cancer (in females) and thyroid cancer, as well as noncancerous conditions of the breast and thyroid. Here we report two cases of male breast cancer occurring in patients with classical CS phenotypes and germline PTEN mutations. The first subject was diagnosed with CS indicated primarily by mucocutaneous papillomatosis, facial trichilemmomas, and macrocephaly with frontal bossing at the age of 31 years. He developed breast cancer at 41 years and subsequently died of the disease. A PTEN mutation, c.802delG, was identified in this subject, yet none of his family members showed evidence of a CS phenotype, suggesting that this PTEN mutation may be a de novo occurrence. The second subject had a CS phenotype including multiple trichilemmomas and thyroid adenoma, developed male breast cancer at 43 years, and died of the disease at 57 years. He was a carrier of a PTEN mutation c.347-351delACAAT that cosegregated with the $C S$ phenotype in affected family members. These two cases of male breast cancer associated with germline PTEN mutations and the CS phenotype suggest that CS may be associated with an increased risk of early onset male as well as female breast cancer.

(f Med Genet 2001;38:159-164)
\end{abstract}

Keywords: PTEN; male breast cancer; Cowden syndrome

Cowden syndrome (CS) is an autosomal dominant cancer susceptibility syndrome characterised by multiple hamartomas. ${ }^{1-4}$ While CS is generally considered a rare condition, it is associated with highly variable, subtle, and protean symptoms and signs, suggesting that it may be underdiagnosed and under-reported. ${ }^{56}$ CS presentation usually occurs in patients in their twenties and is most commonly indicated by mucocutaneous lesions including trichilemmomas, acral and palmoplantar keratoses, and verucoid or papillomatous papules. Other common features include gastrointestinal hamartomas, neurological disorders including macrocephaly and mental retardation, and genitourinary abnormalities including tumours and malformations. ${ }^{5-11}$

The most common cancers associated with CS are breast (in females) and thyroid carcinomas. ${ }^{10}$ Women in CS families have a lifetime risk of developing breast cancer of $25-50 \%$, and an average age of diagnosis 10 years younger than sporadic breast cancer patients. ${ }^{8}{ }^{10}$ As with other hereditary breast cancers, CS associated breast cancers are also more likely than sporadic breast cancers to be multifocal and bilateral in origin. Thyroid cancer occurs in about $3-10 \%$ of CS patients, and these cancers are predominantly follicular carcinomas. ${ }^{812}$ In addition to the hallmark breast and thyroid cancers, malignancies in other tissues have also been reported in CS patients, including glioblastomas, mucocutaneous carcinomas, non-small cell carcinomas of the lung, and various gastrointestinal and genitourinary carcinomas, as reviewed by Eng and Parsons. ${ }^{13}$

$\mathrm{CS}$ is associated with germline mutations in the tumour suppressor gene PTEN (phosphatase and tensin homologue mutated on chromosome ten; also known as $M M A C 1$ or TEP1). PTEN mutations are found in $13-81 \%$ of CS families and the PTEN locus is associated with loss of heterozygosity $(\mathrm{LOH})$ in a subset of CS tumours, depending on ascertainment criteria. ${ }^{14-20}$ The PTEN gene encodes a lipid phosphatase that dephosphorylates phosphatidylinositol 3,4 diphosphate (PtdIns $\left.(3,4) \mathrm{P}_{2}\right)$ and phosphatidylinositol 3,4,5 triphosphate $\left(\operatorname{PtdIns}(3,4,5) \mathrm{P}_{3}\right)$ to PtdIns $(4) \mathrm{P}$ and PtdIns $(4,5) \mathrm{P}_{2}$, respectively. ${ }^{21-23}$ This lipid phosphatase activity participates in regulating the phosphoinositide 3-kinase (PI3K) regulatory network. Thus, while it is not clear which of the many potential targets of the PTEN phosphatase are most relevant to tumour suppression, its involvement in PI3K regulation suggests that it may play a role in both inhibiting cell cycle progression and promoting apoptosis. ${ }^{24-27}$

Since PTEN was characterised as a tumour suppressor, PTEN mutations have been reported in a number of syndromes other than CS. For example, germline mutations in PTEN are associated with $50-60 \%$ of cases of Bannayan-Riley-Ruvalcaba (BRR) syndrome, a multiple hamartoma syndrome showing clinical overlap with CS. ${ }^{19}{ }^{28-33}$ Somatic PTEN mutations have been found at high frequencies in sporadic glioblastomas and endometrial and prostate cancers and at lower frequencies in 

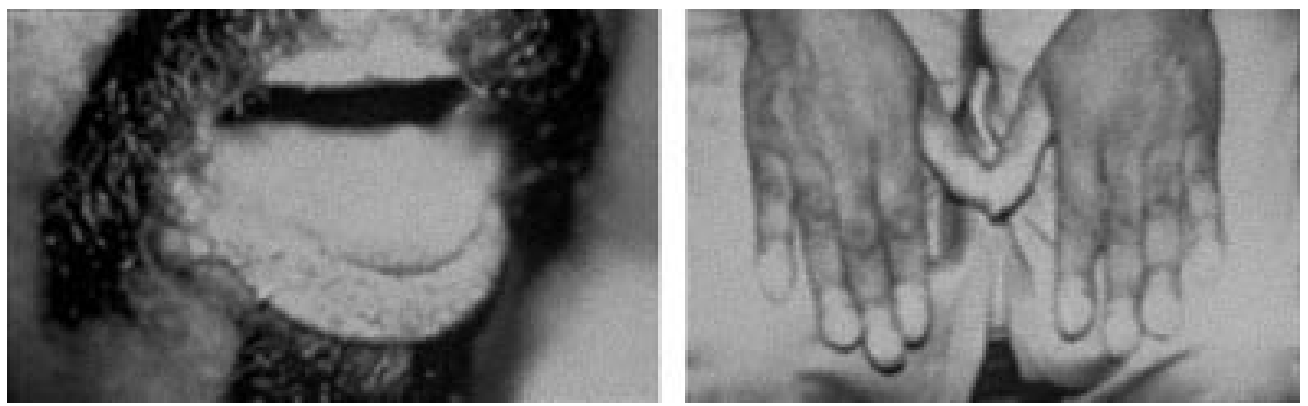

Figure 1 Cowden syndrome in family member III.19. Note the mucocutaneous papillomatosis, facial trichilemmomas, and severe clubbing of the fingers.

cancers of the breast, kidney, thyroid, and colon. ${ }^{18}{ }^{34-37}$ PTEN is now considered one of the most frequently mutated genes in human cancers and may therefore represent a critical pathway required for tumour suppression in a variety of tissues. In this study, we report a case of male breast cancer in a subject with a novel germline PTEN mutation and associated Cowden features and further investigate a second Cowden family with male breast cancer. ${ }^{16}$ These observations suggest that PTEN may play a role in tumour suppression in both male and female breast epithelium.

\section{Materials and methods}

Family 97-80 was ascertained through the Cancer Risk Clinic at the University of Chicago, USA, and family CDst was ascertained at the Kolling Institute of Medical Research, Royal North Shore Hospital, Sydney, Australia. All subjects tested signed informed consent approved by the respective Institutional Review Boards.

Genomic DNA was extracted from peripheral blood using standard protocols. ${ }^{38}$ Screening of the PTEN gene for point mutations, deletions, insertions, or small rearrangements was performed by denaturing gradient gel electrophoresis (DGGE) as previously described. ${ }^{39-42}$ PCR products showing an electrophoretic DGGE variant pattern were reamplified from the original genomic DNA, gel isolated, and purified using the Wizard PCR Preps DNA Purification System (Promega, Madison, WI). Purified PCR products were directly sequenced using the ABI Prism Dye Terminator Cycle Sequencing Ready Reaction Kit (Perkin-Elmer, Norwalk, CT). The cycle sequenced products were electrophoresed on 6\% Long Ranger gels (FMC Bioproducts, Rockland, ME) and analysed on an Applied Biosystems model 373A automated DNA sequencer (Perkin-Elmer).

Restriction digestion of PCR products was performed under the manufacturer's recommendations (New England Biolabs, Beverly, MA).

\section{Results}

Family $97-80$ is a 57 member, four generation kindred with a single affected subject, III.19, a 41 year old male, the youngest of a sibship of 11. He was diagnosed with CS at the age of 31 years when he presented with mucocutaneous papillomatosis, multiple facial trichilemmomas, and macrocephaly with frontal bossing (fig 1). Other phenotypic features included a high arched palate and hamartomas of multiple organs leading to severe bronchiectasis and digital clubbing. A diagnosis of a locally invasive infiltrating ductal carcinoma of the right breast was made at the age of 41 years. The tumour was nuclear and histological grade $2 / 3$, oestrogen receptor positive $(\mathrm{ER}+)$, and with a low $S$ phase fraction. Owing to his severe bronchiectasis requiring supplemental oxygen therapy, the patient was treated conservatively with a mastectomy and Tamoxifen. He died of widespread metastatic disease within two years of diagnosis.

A novel germline mutation in exon 7 of PTEN, c.802delG, predicted to affect splicing, was identified in patient III.19. This probably represents a de novo event because there were no stigmata of CS identified in any other family member (fig 2A). Unfortunately, both parents were dead and could not be tested; one of the proband's sisters, III.12, tested negative for this mutation, and other family members were unwilling to contribute a blood sample for research.

Family CDst is a 23 member, three generation kindred with three members, all sibs in the second generation, exhibiting multiple CS symptoms $^{16}$ (fig 2B). Family member II.5 was diagnosed with breast cancer at the age of 43 years and thyroid adenoma at 47 years. This subject was also diagnosed with multiple trichilemmomas on the arms and legs and mildly dysplastic tubular adenoma of the bowel, but showed no signs of macrocephaly. His breast tumour was reported as invasive ductal carcinoma with none of 17 axillary lymph nodes showing any evidence of metastasis at the time of surgery. The patient subsequently developed hepatic metastases and died of breast cancer at the age of 57 years.

Patient II.4, a 63 year old female, was diagnosed with breast cancer, moderately differentiated adenocarcinoma of the proximal ascending colon, bowel polyps, possible neurofibromatosis, and a brain tumour. Unfortunately, we were unable to determine whether the neurofibromatosis in this patient represents a novel phenotype associated with CS or is associated with an unrelated mutation in a neurofibromatosis susceptibility gene. Neurofibromatosis is an autosomal dominant disorder that is completely penetrant (though variably 
expressive) and would be expected to occur multiple times within a family. However, there were no other reports of neurofibromatosis in this family. It is therefore intriguing to speculate whether the reported neurofibromatosis in this family is associated with CS as are other disorders of the nervous system in this syndrome.

II. 2 was a 72 year old female with invasive ductal carcinoma of the breast, histological grade 2 and $\mathrm{ER}(+)$. Two of 18 axillary lymph nodes had shown metastasis. She also had endometrial carcinoma. A thyroidectomy had been performed at the age of 32 years from which no records were available. Patient II.3, a 65 year old female, was diagnosed with thyroid adenoma but has no other features of CS and is currently alive without cancer. Patient III. 1 was diagnosed with breast cancer in her thirties and died of metastatic disease. Family member I.1 had thyroid cancer and died in her fifties of a cerebral haemorrhage.

Sequence analysis of the proband, II.5, showed that the PTEN mutation associated with CS in this family is c.347351 delACAAT. ${ }^{16}$ This mutation creates an Nsi restriction site that can be used for rapid detection in at risk family members using a PCR assay (fig 3). This deletion occurs in exon 5 upstream of the PTPase core motif, and is predicted to lead to premature truncation of the protein. Four additional family members were screened by PCR and restriction analysis: II.4 was found to share the same mutation as the

A

II

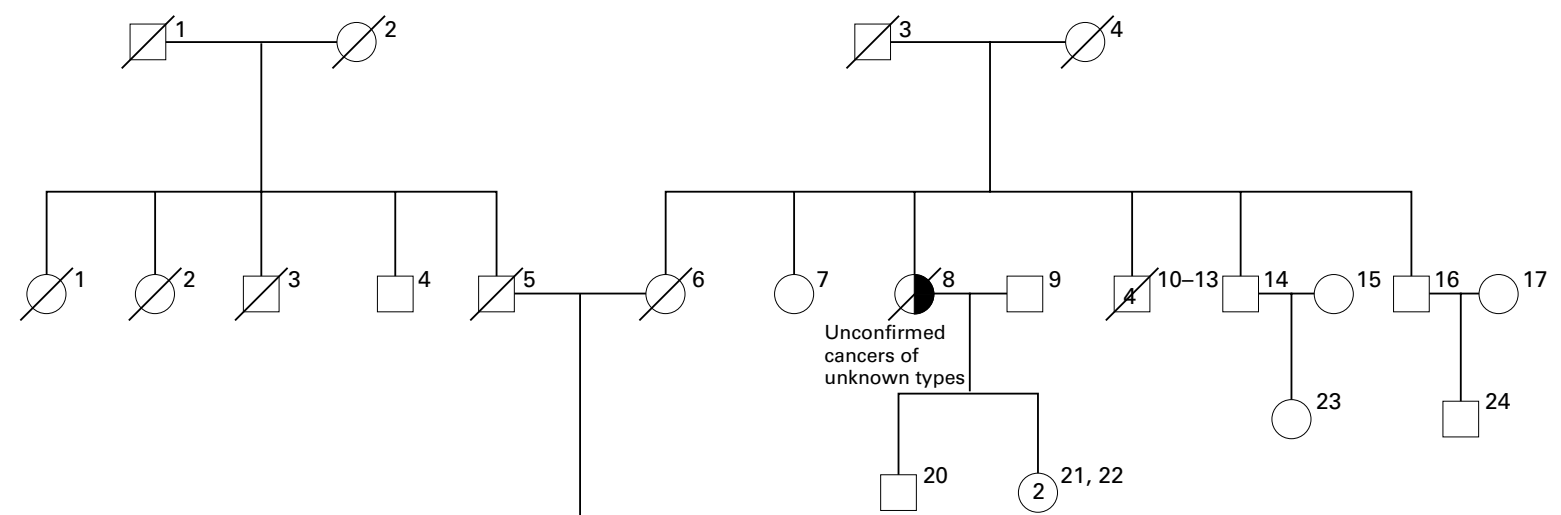

III

IV
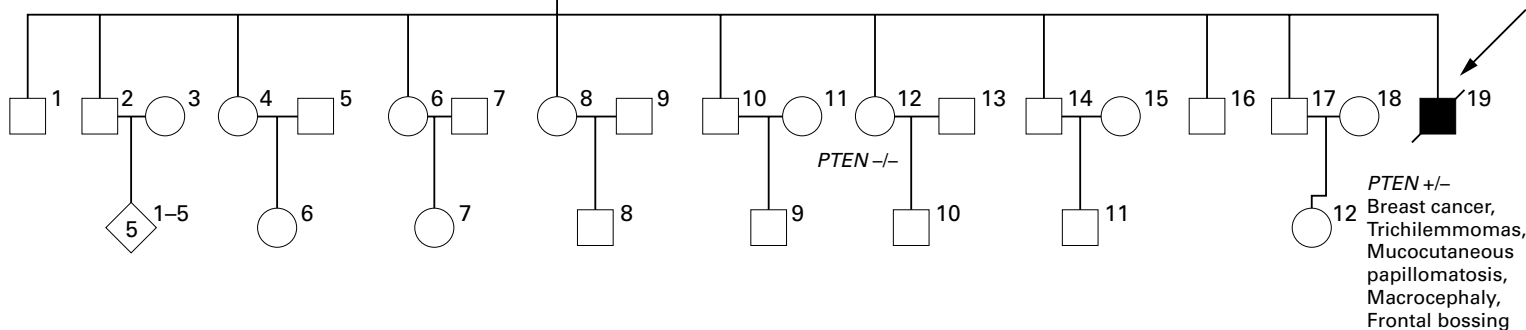

B

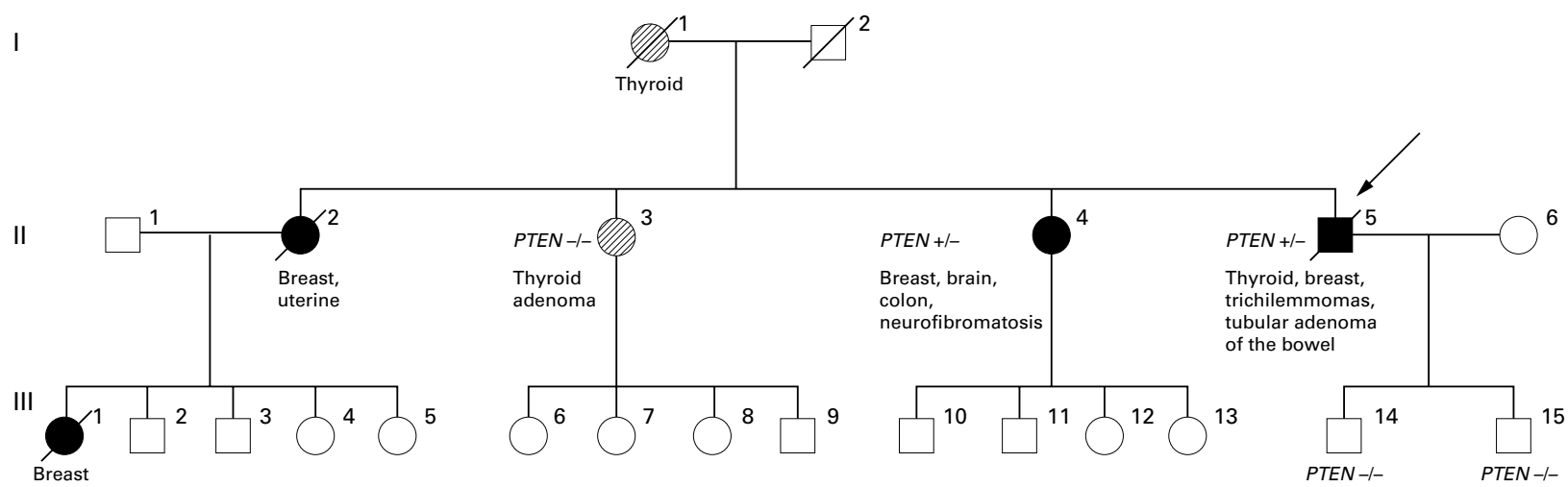

Figure 2 Pedigrees of families with CS and male breast cancer. Affected family members are represented by solid circles (females) or squares (males). Diamonds indicate gender unknown. Hatched circles indicate possible phenocopies. Half circles represent unconfirmed cancer. Numbers within symbols indicate multiple sibs, numbered as indicated above the symbols. +/- indicates that the subject is a carrier of a germline PTEN mutation. -/- indicates that the subject is wild type. Probands with CS are identified by an arrow. (A) Pedigree 97-80. The proband, III.19, was diagnosed with CS at 31 years and breast cancer at 41 years. He carries the germline PTEN c.802delG mutation. (B) Pedigree CDst. The proband, II. 5, was diagnosed with breast cancer at 43 years and CS at 47. II.5 and II. 4 were shown to be carriers of the PTEN germline mutation c.347-351delACAAT. 


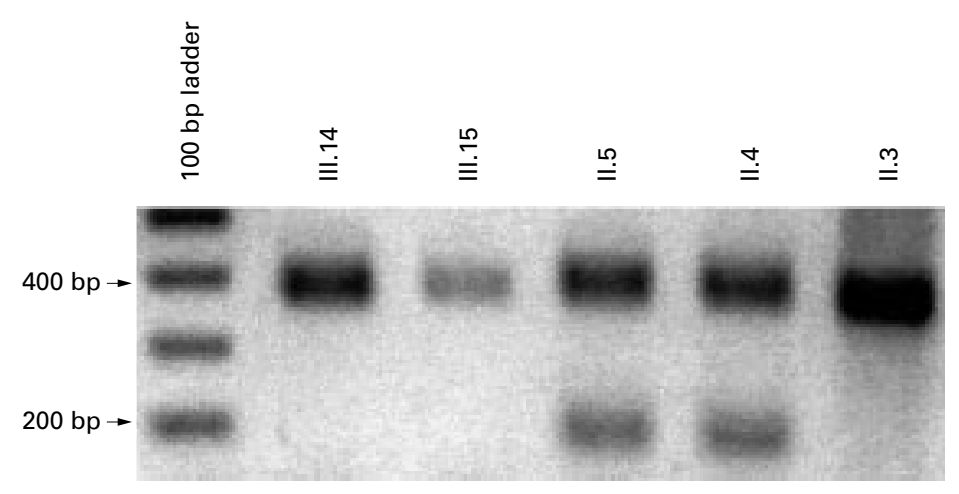

Figure 3 NsiI digestion of PTEN exon 5 PCR product of affected (II.4, II.5) and unaffected (II.3, III.14, III.15) subjects in pedigree CDst. The NsiI restriction site is created in those carrying the c.347-351delACAAT germline PTEN mutation.

proband, while II.3, III.14, and III.15 did not have this mutation. As expected, the PTEN mutation cosegregates with the CS phenotype. However, the thyroid adenoma in patient II. 3 is most likely a sporadic tumour unrelated to CS as this family member does not carry the familial PTEN mutation.

\section{Discussion}

It is currently estimated that $30-86 \%$ of inherited breast cancers in women are caused by germline mutations in highly penetrant susceptibility genes such as $B R C A 1$ and $B R C A 2 .{ }^{43}$ Rarer genetic conditions, such as the LiFraumeni syndrome, Muir-Torre syndrome, Peutz- Jeghers syndrome, ataxia-telangiectasia, and Cowden syndrome also contribute to a small percentage of breast cancer in women. By contrast, it is not known what proportion of male breast cancer is caused by germline mutations in highly penetrant breast cancer susceptibility genes. Male breast cancer typically occurs at $0.5-2.4 \%$ the frequency of female breast cancer, ${ }^{44}$ depending upon geographical location. In the USA, approximately 1000 males are diagnosed with breast cancer each year. ${ }^{45}$ Outside the USA and Europe, Japan has the lowest incidence rate (0.6 cases of male breast cancer per 100000 men), ${ }^{46}$ while some African nations have higher frequencies. In Zambia, for example, male breast cancer accounts for $15 \%$ of all breast cancer cases. $^{47}$

The risk of male breast cancer can increase in cases of increased levels of oestrogen or decreased levels of androgen, such as in cases of testicular injury ${ }^{48}$ or cirrhosis of the liver, which is associated with increased levels of oestrogen. ${ }^{49}$ Men with Klinefelter's syndrome have a 14-50 fold increased risk of developing male breast cancer. ${ }^{50}$ Clinical presentations of male and female breast cancers are similar, but median age of onset in males is later than in females (60 $v 53$ years) and tumours in male breast cancers are generally of higher grade..$^{51-53}$ All histological tumour types that have been characterised in females have also been seen in males with breast cancer. Although genetic markers in male breast cancer remain poorly characterised, a few studies have examined the contribution of markers such as HER2/neu and p53. Amplification of the HER2/neu oncogene has been observed, but reports vary widely concerning its frequency and prognostic value..$^{54-56}$

Germline mutations in the BRCA2 gene have been identified in men with breast cancer and a founder mutation, BRCA2999del5, has been reported to account for nearly $44 \%$ of male breast cancers in Iceland. ${ }^{57-58}$ Overall, males with $B R C A 2$ germline mutations have a $6.3 \%$ probability of developing breast cancer by the age of 70 years, ${ }^{59}$ whereas mutations in the other major female breast cancer susceptibility gene, $B R C A 1$, are not thought to be associated with significant male breast cancer risk. More recently, one primary male breast cancer case was reported in a subject who also had colon cancer and an inherited $M L H 1$ mutation from a family with hereditary non-polyposis colorectal cancer (HNPCC) syndrome. ${ }^{60}$ This suggests that male breast cancer may also occur as an integral tumour in the HNPCC syndrome.

The data presented in this study suggest that germline PTEN mutations contribute to the development of both male and female breast cancer within CS families. Given that PTEN mutations were identified in the germline of the two male breast cancer patients described here, and because germline PTEN mutations are known to increase the risk of breast cancer in females, we believe that the PTEN mutation contributed to male breast cancer development in these CS patients. While we cannot formally exclude the possibility that the cases of male breast cancer in these CS families are phenocopies, we believe that this is highly unlikely. Reasons include the low frequency of male breast cancer in the general population, the young age at diagnoses in these two cases compared to the general population, the presence of other CS manifestations in these two men with breast cancer, and, at least in family CDst, segregation of the germline PTEN mutation in all affected subjects.

To our knowledge, there has been only one previous report of a possible male breast cancer case associated with a PTEN mutation in a CS family. This subject's family showed characteristic cases of skin and uterine abnormalities, along with myomatosis, goitre, and macrocephaly. It was not clear from this study whether the reported male breast involvement was malignant or benign. ${ }^{17}$ Thus, germline mutation of $B R C A 2$, rarely $B R C A 1$ and $M L$ H1, and now PTEN would appear to be associated with the development of both male and female breast cancer. Both men in this report died of metastatic breast cancer. We believe that males with PTEN mutations may have an increased risk for breast cancer and clinicians taking care of CS patients should now become aware of this risk. Further studies to identify a putative role for PTEN mutations in a larger male breast cancer cohort are continuing. 
We are very grateful to the patients who participated in this study. This study was partially supported by grants from the Department of Defence (DAMD17-99-1-9123), the Falk Medical Research Trust (to OIO), the NCRR (MOI RR00055) and CA14599-24 to the University of Chicago Clinica Research Center and Comprehensive Cancer Center, the American Cancer Society (RPG98-211-01CCE to CE), and the National Cancer Institute (P30CA16058 to The Ohio State University Comprehensive Cancer Center).

1 Bardenstein DS, McLean IW, Nerney J, Boatwright RS. Cowden's disease. Ophthalmology 1988;95:1038-41.

2 Gilbert HD, Plezia RA, Pietruk T. Cowden's disease (multiple hamartoma syndrome). F Oral Maxillofac Surg 1985;43 457-60.

3 Thyresson HN, Doyle JA. Cowden's disease (multiple hamartoma syndrome). Mayo Clin Proc 1981;56:179-84.

4 Wade TR, Kopf AW. Cowden's disease: a case report and review of the literature. F Dermatol Surg Oncol 1978;4:45964.

5 Mallory SB. Cowden syndrome (multiple hamartoma syndrome). Dermatol Clin 1995;13:27-31.

6 Schrager CA, Schneider D, Gruener AC, Tsou HC, Peacocke M. Clinical and pathological features of breast disease in Cowden's syndrome: an underrecognized disease in Cowden's syndrome: an underrecognized syndrome with an in
Pathol 1998;29:47-53.

7 Hanssen AM, Fryns JP. Cowden syndrome. 7 Med Genet 1995;32:117-19.

8 Longy M, Lacombe D. Cowden disease. Report of a family and review. Ann Genet 1996;39:35-42.

9 Salem OS, Steck WD. Cowden's disease (multiple hamartoma and neoplasia syndrome). A case report and review of the English literature. $\mathcal{F}$ Am Acad Dermatol 1983;8:686-96.

10 Starink TM, van der Veen JP, Arwert F, de Waal LP, de Lange GG, Gille JJ, Eriksson AW. The Cowden syndrome: a clinical an

11 Wade TR. Cowden's disease. Cutis 1979;24:537-41.

12 Eng C. Cowden syndrome. F Genet Couns 1997;6:181-92. Kinzler K, eds. The genetic basis of human cancer. New York: McGraw-Hill, 1998:519-25.

14 Liaw D, Marsh DJ, Li J, Dahia PL, Wang SI, Zheng Z, Bose S, Call KM, Tsou HC, Peacocke M, Eng C, Parsons R. Germline mutations of the PTEN gene in Cowden disease, Germline mutations of the PTEN gene in Cowden disease, an inherited brea

15 Marsh DJ, Dahia PL, Coulon V, Zheng Z, Dorion-Bonnet F, Call KM, Little R, Lin AY, Eeles RA, Goldstein AM, Hodgson SV, Richardson AL, Robinson BG, Weber HC, Longy $M$, Eng C. Allelic imbalance, including deletion of PTEN/MMACI, at the Cowden disease locus on 10q22 23, in hamartomas from patients with Cowden syndrome and germline PTEN mutation. Genes Chrom Cancer 1998 21:61-9.

16 Marsh DJ, Coulon V, Lunetta KL, Rocca-Serra P, Dahia PL, Zheng Z, Liaw D, Caron S, Duboue B, Lin AY, Richardson AL, Bonnetblanc JM, Bressieux JM, CabarrotMoreau A, Chompret A, Demange L, Eeles RA, Yahanda AM, Fearon ER, Fricker JP, Gorlin RJ, Hodgson SV, AM, Fearon ER, Fricker JP, Gorlin RJ, Hodgson SV, Huson S, Lacombe D, Eng C. Mutation spectrum and
genotype-phenotype analyses in Cowden disease and genotype-phenotype analyses in Cowden disease and with germline PTEN mutation. Hum Mol Genet 1998; with germ $507-15$

17 Nelen MR, van SW, Peeters EA, Hassel MB, Gorlin RJ, Hamm H, Lindboe CF, Fryns JP, Sijmons RH, Woods DG, Mariman EC, Padberg GW, Kremer H. Germline mutations in the PTEN/MMAC1 gene in patients with Cowden disease. Hum Mol Genet 1997;6:1383-7.

18 Teng DH, Hu R, Lin H, Davis T, Iliev D, Frye C, Swedlund B, Hansen KL, Vinson VL, Gumpper KL, Ellis L, El-Naggar A, Frazier M, Jasser S, Langford LA, Lee J, Mills GB, Pershouse MA, Pollack RE, Tornos C, Troncoso P, Yung WK, Fujii G, Berson A, Steck PA. MMAC1/PTEN mutations in primary tumor specimens and tumor cell lines. Cancer Res 1997;57:5221-5.

19 Marsh DJ, Kum JB, Lunetta KL, Bennett MJ, Gorlin RJ, Ahmed SF, Bodurtha J, Crowe C, Curtis MA, Dasouki M, Dunn T, Feit H, Geraghty MT, Graham JM, Jr., Hodgson SV, Hunter A, Korf BR, Manchester D, Miesfeldt S, Murday VA, Nathanson KL, Parisi M, Pober B, Romano C, day VA, Nathanson KL, Parisi M, Pober B, Romano C, Eng C. PTEN mutation spectrum and genotypephenotype correlations in Bannayan-Riley-Ruvalcaba syn-
drome suggest a single entity with Cowden syndrome. Hum drome suggest a single entity

20 Tsou HC, Teng DH, Ping XL, Brancolini V, Davis T, Hu R, Xie XX, Gruener AC, Schrager CA, Christiano AM, Eng C, Steck P, Ott J, Tavtigian SV, Peacocke M. The role of MMAC1 mutations in early-onset breast cancer: causative in association with Cowden syndrome and excluded in BRCA1-negative cases. Am f Hum Genet 1997;61:1036-43.

21 Furnari FB, Huang HJ, Cavenee WK. The phosphoinositol phosphatase activity of PTEN mediates a serum-sensitive G1 growth arrest in glioma cells. Cancer Res 1998;58:5002-

22 Maehama T, Dixon JE. The tumor suppressor, PTEN/ MMAC1, dephosphorylates the lipid second messenger, phosphatidylinositol 3,4,5-trisphosphate. F Biol Chem 1998;273:13375-8.

23 Myers MP, Pass I, Batty IH, Van der Kaay J, Stolarov JP, Hemmings BA, Wigler MH, Downes CP, Tonks NK. The lipid phosphatase activity of PTEN is critical for its tumor
Suppressor function. Proc Natl Acad Sci USA 1998;95: 13513-8.

24 Cardone MH, Roy N, Stennicke HR, Salvesen GS, Franke TF, Stanbridge E, Frisch S, Reed JC. Regulation of cell death protease caspase- 9 by phosphorylation. Science 1998; 282:1318-21.

25 Cross DA, Alessi DR, Cohen P, Andjelkovich M, Hemmings $\mathrm{BA}$. Inhibition of glycogen synthase kinase- 3 by insulin mediated by protein kinase B. Nature 1995;378:785-9.

26 Datta SR, Dudek H, Tao X, Masters S, Fu H, Gotoh Y, Greenberg ME. Akt phosphorylation of BAD couples survival signals to the cell-intrinsic death machinery. Cell 1997;91:231-41.

27 Diehl JA, Cheng M, Roussel MF, Sherr CJ. Glycogen synthase kinase-3beta regulates cyclin D1 proteolysis and subcellular localization. Genes Dev 1998;12:3499-511.

28 Bannayan GA. Lipomatosis, angiomatosis, and macrencephalia. A previously undescribed congenital syndrome. Arch Pathol 1971;92:1-5.

29 Fargnoli MC, Orlow SJ, Semel-Concepcion J, Bolognia JL. Clinicopathologic findings in the Bannayan-RileyRuvalcaba syndrome. Arch Dermatol 1996;132:1214-8.

30 Gorlin RJ, Cohen MM Jr, Condon LM, Burke BA. Bannayan-Riley-Ruvalcaba syndrome. Am $7 \mathrm{Med}$ Genet 1992;44:307-14

31 Longy M, Coulon V, Duboue B, David A, Larregue M, Eng C, Amati P, Kraimps JL, Bottani A, Lacombe D, Bonneau D. Mutations of PTEN in patients with Bannayan-RileyRuvalcaba phenotype. f Med Genet 1998;35:886-9.

32 Marsh DJ, Dahia PL, Zheng Z, Liaw D, Parsons R, Gorlin RJ, Eng C. Germline mutations in PTEN are present in Bannayan-Zonana syndrome. Nat Genet 1997;16:333-4.

33 Zonana J, Rimoin DL, Davis DC. Macrocephaly with multiple lipomas and hemangiomas. F Pediatr 1976;89:600-3.

34 Chen ST, Yu SY, Tsai M, Yeh KT, Wang JC, Kao MC, Shih MC, Chang JG. Mutation analysis of the putative tumor suppression gene PTEN/MMAC1 in sporadic breast cancer. Breast Cancer Res Treat 1999;55:85-9.

35 Eng C. Genetics of Cowden syndrome: through the looking glass of oncology. Int F Oncol 1998;12:701-10.

36 Steck PA, Pershouse MA, Jasser SA, Yung WK, Lin H, Ligon AH, Langford LA, Baumgard ML, Hattier T, Davis T, Frye C, Hu R, Swedlund B, Teng DH, Tavtigian SV. Identification of a candidate tumour suppressor gene, MMAC1, at chromosome $10 \mathrm{q} 23.3$ that is mutated in multiple advanced cancers. Nat Genet 1997;15:356-62.

37 Whang YE, Wu X, Suzuki H, Reiter RE, Tran C, Vessella RL, Said JW, Isaacs WB, Sawyers CL. Inactivation of the tumor suppressor PTEN/MMAC1 in advanced human prostate cancer through loss of expression. Proc Natl Acad Sci USA 1998;95:5246-50.

38 Mathew CG, Chin KS, Easton DF, Thorpe K, Carter C, Liou GI, Fong SL, Bridges CD, Haak H, Kruseman AC. A linked genetic marker for multiple endocrine neoplasia type 2A on chromosome 10. Nature 1987;328:527-8.

39 Marsh DJ, Dahia PL, Caron S, Kum JB, Frayling IM, Tomlinson IP, Hughes KS, Eeles RA, Hodgson SV, Murday VA, Houlston R, Eng C. Germline PTEN mutations in
Cowden syndrome-like families. F Med Genet 1998;35:8815 .

40 Marsh DJ, Roth S, Lunetta KL, Hemminki A, Dahia PL, Sistonen P, Zheng Z, Caron S, van Orsouw NJ, Bodmer WF, Cottrell SE, Dunlop MG, Eccles D, Hodgson SV, Jarvinen H, Kellokumpu I, Markie D, Neale K, Phillips R, Rozen P, Syngal S, Vijg J, Tomlinson IP, Aaltonen LA, Eng C. Exclusion of PTEN and 10q22-24 as the susceptibility locus for juvenile polyposis syndrome. Cancer Res 1997;57: 5017-21.

41 Guldberg P, thor Straten P, Birck A, Ahrenkiel V, Kirkin AF, Zeuthen J. Disruption of the MMAC1/PTEN gene by deletion or mutation is a frequent event in malignant melanoma. Cancer Res 1997;57:3660-3.

42 Mutter GL, Lin MC, Fitzgerald JT, Kum JB, Baak JP, Lees JA, Weng LP, Eng C. Altered PTEN expression as a diagnostic marker for the earliest endometrial precancers. $\mathcal{F}$ Natl Cancer Inst 2000;92:924-30.

43 Ford D, Easton DF, Stratton M, Narod S, Goldgar D, Devilee P, Bishop DT, Weber B, Lenoir G, Chang CJ, Sobol H, Teare MD, Struewing J, Arason A, Scherneck S, Peto J, Rebbeck TR, Tonin P, Neuhausen S, Barkardottir R, Eyfjord J, Lynch H, Ponder BA, Gayther SA, Zelada HM. Genetic heterogeneity and penetrance analysis of the $B R C A 1$ and $B R C A 2$ genes in breast cancer families. The Breast Cancer Linkage Consortium. Am f Hum Genet 1998;62:676-89.

44 Anan H, Okazaki M, Fujimitsu R, Hamada Y, Sakata N, Nanbu M. Intracystic papillary carcinoma in the male breast. A case report. Acta Radiol 2000;41:227-9.

45 Miller B, Ries L, Hankey B, Kosary C, Harras A, Devesa S, Edwards B. SEER cancer statistics review: 1973-1990. NIH Pub No 93-2789. Bethesda, MD: National Cancer Institute, 1993.

46 Muir C, Waterhouse J, Mack T, Powell J, eds. Cancer incidence in five continents. Lyon: IARC Science Publishers, 1987.

47 Bhagwandeen S. Carcinoma of the male breast in Zambia. East Afr Med F 1972;49:89-93.

48 Thomas DB, Jimenez LM, McTiernan A, Rosenblatt K, Stalsberg H, Stemhagen A, Thompson WD, Curnen MG, Satariano W, Austin DF. Breast cancer in men: risk factors with hormonal implications. Am f Epidemiol 1992;135:73448 
49 Misra SP, Misra V, Dwivedi M. Cancer of the breast in a male cirrhotic: is there an association between the two? Am male cirrhotic: is there an associat

50 Evans DB, Crichlow RW. Carcinoma of the male breast and Klinefelter's syndrome: is there an association? CA Cancer $\mathcal{f}$ Clin 1987;37:246-51

51 Harris J, Morrow M, Norton L. Malignant tumors of the breast. In: Cancer: principles and practice of oncology. 5th ed. Philadelphia: Lippincott-Raven, 1997:1557-616.

52 Horm J, Asire A, Young J, eds. SEER program: cancer Publication No. 85-1837. Bethesda, MD: US Departmen of Health and Human Services, 1984

53 Moore M. Male breast cancer. In: Harris J, Lippman M, Morrow M, eds. Diseases of the breast. New York, NY Lippincott-Raven, 1996:859-63.

54 Dawson PJ, Paine TM, Wolman SR. Immunocytochemical characterization of male breast cancer. Mod Pathol 1992;5: 621-5.

55 Fox SB, Day CA, Rogers S. Lack of c-erbB-2 oncoprotein expression in male breast carcinoma. F Clin Pathol 1991;44: $960-1$.
56 Joshi MG, Lee AK, Loda M, Camus MG, Pedersen C, Heatley GJ, Hughes KS. Male breast carcinoma: an evaluation of prognostic factors contric outcome. Cancer 1996;77:490-8.

57 Thorlacius S, Olafsdottir G, Tryggvadottir L, Neuhausen S, Jonasson JG, Tavtigian SV, Tulinius H, Ogmundsdottir HM, Eyfjord JE. A single BRCA2 mutation in male and female breast cancer families from Iceland with varied cancer phenotypes. Nat Genet 1996;13:117-19.

58 Thorlacius S, Sigurdsson S, Bjarnadottir H, Olafsdottir G, Jonasson JG, Tryggvadottir L, Tulinius H, Eyfjord JE. Study of a single BRCA2 mutation with high carrier frequency in a small population. Am f Hum Genet 1997;60:1079-84.

59 Easton DF, Steele L, Fields P, Ormiston W, Averill D, Daly PA, McManus R, Neuhausen SL, Ford D, Wooster R, Cannon AL, Stratton MR, Goldgar DE. Cancer risks in two large breast cancer families linked to BRCA2 on chromosome 13q12-13. Am f Hum Genet 1997;61:120-8.

60 Boyd J, Rhei E, Federici MG, Borgen PI, Watson P, FrankBoyd J, Rhei E, Federici MG, Borgen PI, Watson P, Frank-
lin B, Karr B, Lynch J, Lemon SJ, Lynch HT. Male breast lin B, Karr B, Lynch J, Lemon SJ, Lynch HT. Male breast
cancer in the hereditary nonpolyposis colorectal cancer cancer in the hereditary nonpolyposis colorectal
syndrome. Breast Cancer Res Treat 1999;53:87-91. 